\title{
The role of Allied Health Professions and Nursing Research Internships in developing a research culture: a mixed-methods exploration of stakeholder perspectives
}

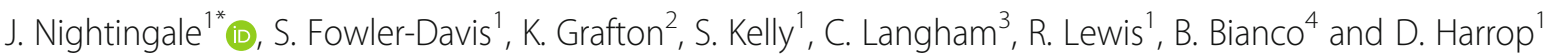

\begin{abstract}
Background: Developing research capability and capacity within the healthcare professions is a challenge throughout diverse international settings. Within England, the National Institute for Health Research aimed to address these challenges through the Integrated Clinical Academic (ICA) research careers escalator for nurses, midwives and allied health professionals. Poor academic progression has been identified in the advanced stages of the pathway, though progression from the earlier entry point (Internship) has not previously been investigated. A national evaluation of four completed Internship cohorts was undertaken to explore stakeholder perspectives and progression beyond the Internship programme.

Methods: A mixed methods project used sequential qualitative and quantitative data collection phases commencing with two stakeholder focus groups $(n=10)$; the findings informed the development of an online survey distributed to previous cohorts of interns $(n=104)$, their managers $(n=12)$ and academic mentors $(n=36)$. Eight semi-structured interviews subsequently explored the challenges and opportunities afforded by the internships. Thematic analysis was used to review qualitative data from focus groups and interviews, with survey data analysed and displayed using descriptive statistics. Synthesis of data from each phase is displayed within the four level evaluation framework outlined within the New World Kirkpatrick ${ }^{\circledast}$ Training Evaluation Model.

Results: Important regional differences exist yet the internships are highly valued by all stakeholders. Representation varied between different professions, with nursing and some service-based professions poorly represented. All interns successfully completed the programme $(n=104)$, with evidence of positive impacts on interns, colleagues and patient care. Balancing research commitments with clinical activity was challenging; middle managers were seen as gatekeepers to programme success. Progression to the next stage of the ICA pathway is highly competitive and was achieved by only a quarter of interns; access to mentors outside of the funded programme is vital for a successful transition.

(Continued on next page)
\end{abstract}

\footnotetext{
* Correspondence: j.nightingale@shu.ac.uk

'Department of Allied Health Professions, Sheffield Hallam University, Sheffield, UK

Full list of author information is available at the end of the article
}

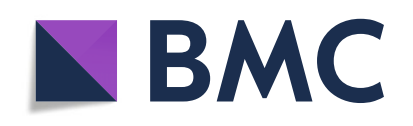

(- The Author(s). 2020 Open Access This article is licensed under a Creative Commons Attribution 4.0 International License, which permits use, sharing, adaptation, distribution and reproduction in any medium or format, as long as you give appropriate credit to the original author(s) and the source, provide a link to the Creative Commons licence, and indicate if changes were made. The images or other third party material in this article are included in the article's Creative Commons licence, unless indicated otherwise in a credit line to the material. If material is not included in the article's Creative Commons licence and your intended use is not permitted by statutory regulation or exceeds the permitted use, you will need to obtain permission directly from the copyright holder. To view a copy of this licence, visit http://creativecommons.org/licenses/by/4.0/. The Creative Commons Public Domain Dedication waiver (http://creativecommons.org/publicdomain/zero/1.0/) applies to the data made available in this article, unless otherwise stated in a credit line to the data. 
(Continued from previous page)

Conclusions: The Internship programme succeeds in providing a range of important early experiences in research, though progression beyond the programme is challenging due, in part, to a widening gap between Internship and the next level of the ICA framework. Vital mentorship support to bridge this gap is threatened by a lack of time and funding; therefore, the pursuit of a clinical-academic career will continue to be elusive for many nurses and allied health professionals. A partnership approach to clinical academic support at institutional level is needed with several international models offering alternative strategies for consideration.

Keywords: Research capacity development, Internship, research, mixed methods, evaluation, allied health

\section{Background}

Nursing, midwifery and the allied health professions (NMAHP) are, in combination, the largest staff group within health services, representing potential new capacity for clinical academic research in international health systems [1]. The term 'Clinical Academic' has been adopted in the United Kingdom to describe clinicians (doctors and healthcare professionals) who have a role that combines treating patients with undertaking research; they may have employment contracts which span both healthcare and higher education. The combined role encourages research that is cutting edge and supports innovations in clinical practice, thus driving forwards evidence-based practice and evidence-based medicine within the National Health Service (NHS).

Traditional educational approaches including taught provision, informal mentorship and in-job training programmes may be effective in developing research awareness in early career healthcare staff; however, the implementation of clinical academic roles has required a more formalised approach. To facilitate the adoption of clinical academic roles within the NMAHP workforce, the National Institute for Health Research (NIHR) implemented the Integrated Clinical Academic (ICA) careers programme. Practitioners apply for individual awards that progress research knowledge from premasters through doctoral study to senior independent clinical research. The Internship is the entry level programme that offers an insight into clinical academic careers; it is open to registered NMAHP staff [2] without any formal research training and who are employed within the NHS. Recruitment is competitive and must show a clear potential for benefiting patients and the public.

Funded by Health Education England (HEE), 10 Internship programmes are delivered by a range of providers, including Higher Education Institutions, HEE subsidiaries and one NHS Trust; all are overseen by HEE on a regional basis in England. The contrasting approaches to commissioning at a regional level result in contrasting delivery (Table 6 Appendix), including bespoke educational packages to small numbers of students, or structured learning offered to higher numbers across a larger geographical area. Applicant selection criteria onto these programmes also varies regionally.

Many health and care organisations and government departments invest in research capacity development in healthcare [3] and it is a moral and ethical imperative to develop, shape and evaluate this activity [4]. The NIHR has invested substantially in training over the last 10 years, though they recognise both structural and cultural barriers to clinical academic progression [5]. While the benefits to individual development can be demonstrated at a service and patient level, progression beyond Masters level for NMAHPs is disappointing $[5,6]$. The role of the Internship level in preparing NMAHPs for an ICA career is unknown. In this context and following the completion of four annual intakes (2014-2017), a mixed methods evaluation was commissioned by HEE to examine the impact of the programme in terms of participant progression and stakeholder perspectives.

To inform the evaluation, a review of the literature was undertaken using search terms related to (1) NMAHPs; (2) post-registration research education; and (3) barriers and facilitators to enhancing research capability and capacity. Searches were undertaken on MEDLINE (EBSCO) and CINAHL, with grey literature identified by consulting with expert stakeholders. All papers yielded from the database searches were assessed for relevance during title and abstract screening and further appraisal of context and study design was undertaken during full-text reading. The literature offered context to the primary investigation and was a lens through which to understand policy and planning issues [7] related to embedding a culture of research.

The literature search identified that a clinical academic is a health professional working clinically and involved in academia to try and find better health outcomes for practice (evidence-based medicine or evidence-based practice); they appear to be highly valued by a range of stakeholders in different international settings. Most importantly, clinical academics are seen as the gatekeepers for the dissemination of information by translating research into clinical practice [8-13]. Opportunities for NMAHPs to engage in clinical academic roles in the United Kingdom are limited [14]; fewer than $0.1 \%$ of the 
NMAHP workforce is engaged in active research [15], compared to $5 \%$ of the medical workforce. While postgraduate studies are recognised globally as a tool for legitimately strengthening clinical credibility and confidence [16], the United Kingdom NMAHP workforce lags behind countries such as Poland and South Africa in the percentage with a postgraduate qualification [17-19].

Aiming to address these imbalances the Association of United Kingdom University Hospitals generated a target of $1 \%$ of allied health staff in clinical academic roles by 2030 [20], though concerns have been raised regarding organisational readiness to achieve the ambitious target [21]. Organisational readiness is noted by Slade et al. [22] to consist of four parallel requirements for embedding a culture of NMAHP research into organisations, as follows:

1) Allied health research policies, regulation, governance and organisational structures that value evidence-based practice;

2) Research capability, receptivity, advocacy and literacy of healthcare leaders;

3) Organisational factors including dedicated staff research positions, time allocated to research, mentoring, professional education and research infrastructure, and partnerships with universities;

4) Individual attributes of clinicians, including research skills and capabilities, motivation, and participation in research teams.

The 'ideal' organisational approach presented above aims to create a clinical academic infrastructure in NMAHP services that may in turn sustain growth in research activity [23]. Other strategies for capability and capacity-building focus on embedding dedicated NMAHP research positions [2, 24] and offering research skills training, research bursaries and mentoring $[2,25]$. While NMAHPs are clearly interested in clinical academic careers [6], there is often uncertainty about the best way to navigate a clinical academic career pathway [26]. The NIHR Research Internships offer an initial opportunity for NMAHPs to undertake a small research project through funded backfill and mentorship. Effective research supervision enables a tangible outcome toward the next stage of development usually a master's degree or application to the next ICA pathway stage (Pre-Doctoral Clinical Academic Fellowship; PCAF) [27, 28].

Internationally, variations on the NIHR Internship model are noted, with performance managed against a range of measures, including completion rates [29]. The majority of research interns have a very positive experience [17, 30-33]. They also report increased confidence and competence, job satisfaction, increased knowledge and skills for hands-on practice, critical thinking in practice, changing practitioner-patient relationships and enhanced communication skills [9, 16-18, 30, 33-39].

Beyond the Internships, the benefits are wide-ranging and long-lasting and include encouraging others, greater involvement in decision-making, increase in motivation, confidence and assertiveness skills, positive impact on service and patient care, increased confidence in writing and speaking skills, and opportunities to teach $[9,16-$ 18, 30, 33-40]. Research opportunities following the Internship include integration into a research team, conducting their own research and being a Principal investigator, or being involved in the development of research projects $[9,17,33,40]$.

Internationally cited structural and organisational barriers to progression from research Internships include a recognition of low pay for research-related roles compared with the expected responsibility [17, 30, 34, 36]. While there are examples of such roles in the United States leading to financial reward during and post completion of internships and post-graduate study [36], the lack of financial support for internships was seen as a fundamental barrier internationally $[17,18,33,36]$. Additionally, the lack of time release (for both Interns and mentors) and impingement on the work-life balance was often cited as a major conflict $[9,18,33,36,38]$. With these potential opportunities and barriers in mind, the evaluation study aimed to explore stakeholder perceptions of the benefits and challenges of the HEE/NIHR Research Internship model, alongside reviewing intern research career progression within and beyond the Internship. This is the first study exploring the Internship programme from a national perspective and will offer funders, policy-makers, educators and research leaders a valuable insight into the potential impact of the programme as a catalyst for promoting research careers and a research culture. Four annual Internship cohorts provide the intended study population; therefore, the career progression findings will relate to the short-tomedium-term impacts of the Internship programme.

\section{Methodology \\ Methodological design}

A mixed methodology project combined qualitative with quantitative data collection in a sequential manner; phase 1 (literature review and focus groups) analysis informed the development of tools for phase 2 (survey and interviews). The New World Kirkpatrick ${ }^{\circ}$ Model [41], developed from a well-established process for recognising the outcomes of training and development [42], was then used as a deductive framework to integrate findings from each phase of the project. The New World model offers subtle changes over the earlier model to address the complexities of modern learning environments [43] 
and consists of four levels of evaluation $(1=$ reaction; 2 = learning; 3 =behaviour; 4 =results/impact). The evaluation focused primarily on Level 4 (desired impact) with indicators of success being (1) participant progression (continuation of clinical academic activity) and (2) stakeholder engagement in the programme delivery and outcomes.

The project was submitted to the institutional Research Ethics Committee in two stages for ethical approval (Ethics ID: ER10500858; ER12442076). Participant information leaflets and consent forms were developed and all responses were anonymised; participants were assured of confidentiality and right to withdraw until completion of data analysis.

\section{Phase 1 data collection and development of phase 2 tools Stakeholder focus groups}

Two focus groups of expert stakeholders $(n=10)$ were invited to highlight key issues and topics for inclusion in the survey and interviews. The stakeholders were selected in consultation with the steering group to promote representation from different geographical regions and different stakeholder groups, and included programme commissioners [4], programme providers [3], academic mentors [1] and graduate interns [2]. The focus groups were facilitated by two researchers and were audio recorded and later transcribed.

The key questions asked of the focus group were the following:

(1) What are the similarities and differences between the different regional internship programmes?

(2) What does success look like for the different stakeholders?
(3) What are the potential barriers and enablers to 'success'?

(4) Can we define the 'key ingredients' for success?

A thematic analysis was based on coding and categorisation of the focus group data to identify a 'topics guide' for the survey and interview (Table 1). The first two themes identified regional and professional disparities and the second two themes referred to the professional barriers and enablers to accessing the 10 regional Internship programmes.

\section{Survey development}

The literature and focus group themes were applied to survey development by an expert group who are familiar with Internship training programmes. The questions were grouped into three sections relevant to interns, their managers and their academic mentors, and included both closed and open-ended question groups. Filter questions at the start of the survey enabled the respondents to complete the questions relevant to their group. The survey was hosted on the Qualtrics ${ }^{\mathrm{Tm}}$ online survey platform (Qualtrics, Provo, UT) [44] and the Qualtrics software-supported data analysis was via descriptive statistics; thematic analysis was undertaken of any open text comments. The survey was piloted by the steering group (including external representatives) and by the research team (including two graduate interns and an Internship mentor) for content, question flow and usability on computers and mobile phone devices. The Director or Course Leader of each of the HEEfunded Internship programmes in England $(n=10)$ was contacted and requested to provide contact emails of interns, managers and mentors of completed cohorts (Internship alumni). An email, with a link to the online

Table 1 Stakeholder focus group themes

\begin{tabular}{ll}
\hline Key themes & Sub-themes \\
\hline 1. Programme and regional variations: & $\cdot$ No standardisation in recruitment and outcome metrics \\
& $\cdot$ Lack of communication channels post internship \\
$\begin{array}{ll}\text { 2. Internship professional differences and } \\
\text { characteristics }\end{array}$ & $\cdot$ AHPs better represented than nurses, some AHPs rarely represented \\
& $\cdot$ Information dissemination variable across settings (e.g. poor representation in the community \\
& setting) \\
& $\cdot$ Previous Masters experience as a barrier or facilitator contested and debated \\
3. Barriers to success & $\cdot$ Influence of research culture of organisation \\
& $\cdot$ Middle managers are gatekeepers to progression \\
& $\cdot$ Gap between Internship and pre-doctorate NIHR level widening \\
& $\cdot$ Lack of joined up approaches (various research initiatives) \\
& $\cdot$ Supervisory relationship is key to success and continuation \\
4. Enablers of success & $\cdot$ Should be intern driven \\
& $\cdot$ Showcase impact on service transformation and culture
\end{tabular}


survey, was cascaded to all contact emails on the three collated email lists (interns, managers and mentors; $n=$ 520), with two subsequent reminders issued.

\section{Interview development}

Survey respondents were invited to provide their contact details if willing to participate in the next phase of the project. A sampling strategy ensured that interns, managers and mentors with potentially different experiences were approached from different geographical regions. Ten participants were initially contacted for a one-toone telephone interview guided by a semi-structured interview schedule that explored their experiences of recruitment and admission, the programme itself, and experiences subsequent to the internship. Interviews were audio recorded and later transcribed in full. Thematic analysis identified key themes and quotations [45].

\section{Results}

\section{Participant demographics}

The link to the survey was sent to 317 Interns, 100 mentors and 103 line managers (Table 2); however, a large number of the intern (university) emails were no longer active, resulting in lower than expected response rates. While data was captured on the range of different regions and programmes, the responses for some categories was small, so only the national combined data is presented. The response rate for graduated interns was 33\% $(n=104 / 317)$ and for mentors it was $36 \%(n=36 / 100)$. While this is lower than anticipated, it is nevertheless greater than published averages for online survey response rates (29\%) [46]. There was no opportunity to increase response rates as many of the emails supplied were nonfunctional. However, the intern responses are considered representative as they equate to over one-quarter of the total population of funded interns.

The interns were predominantly female (86.5\%), equally spread across age range categories from 25 to 54 years. Most interns held a BSc, although 27.8\% $(n=29)$ held a post-registration Masters level award. Most interns now worked in secondary care (United Kingdom Agenda for Change Bands 6 and 7); however, a significant number occupied a Band 8 position (senior leadership or consultant practitioner). The interns had variable research experience prior to commencing the internship. The majority of mentors $(75.6 \%, n=28)$ held PhDs and were University based.

Semi-structured interviews were undertaken with eight participants from different geographical regions, including two line managers, two academic mentors and four graduate interns.

\section{Framework for data presentation}

Analysis of data from Phase 2 (survey and interviews) is combined and presented within the four-level evaluation framework outlined within the New World Kirkpatrick Model. Each level has been interpreted in the context of the internship programme evaluation as demonstrated in Table 3.

Level 1 analysis - reaction (experiences of the Internship) The 104 responding Interns included 38.4\% registered with the Nursing and Midwifery Council (NMC) and 56.7\% registered with the Health and Care Professions Council (HCPC); this latter category included representation from 11 of 13 recognised Allied Health Profession (AHP) groups. The representation of professions across interns, managers and mentors is seen in Fig. 1. Of the 36 mentors who responded, $47 \%$ identified as clinical academics and $50 \%$ as university academics, with $11 \%$ having successfully completed advanced stages of the ICA pathway (Doctoral or Post-Doctoral studies).

All survey and interview participants were very supportive of the concept of the HEE/NIHR Internship. While competition for places was strong, a number of issues regarding fair and equitable access to programmes were raised in both survey and interview responses. Respondents recognised the predominance of nurses and some AHP groups, suggesting that the researchreadiness and opportunities afforded to the professional groups differ:

"... the smaller professions like therapeutic radiographers who don't have really established networks for research... some of the small professions don't even know that this [internship] exists ..." (Line Manager 1)

Participants highlighted that Internship programmes in different regions had variable admissions criteria, with some considering Masters level study an advantage and others seeing this as a barrier. This was assumed to be because each programme was set up with a different outcome in mind.

"When I've spoken to people outside of the region there isn't a set transparent clear process on how people get selected for these courses ... it could seem quite unfair." (Intern 5)

"[Here] it's structured slightly differently to in other parts of the country ...it was specifically designed to support clinicians to bridge the gap between masters level and PhD level learning...in other parts of the country it's more of an introduction to research..." (Intern 8) 
Table 2 Survey respondent demographics

\begin{tabular}{|c|c|c|c|c|}
\hline Category & Options & $\begin{array}{l}\text { Graduated } \\
\text { interns }^{\mathrm{a}}\end{array}$ & $\begin{array}{l}\text { Academic } \\
\text { mentors }\end{array}$ & $\begin{array}{l}\text { Line } \\
\text { managers }\end{array}$ \\
\hline \multicolumn{2}{|l|}{ No. of surveys distributed } & 317 & 100 & 103 \\
\hline \multicolumn{2}{|c|}{ No. of responses received (percentage response rate) } & $104(33 \%)$ & $36(36 \%)$ & $12(12 \%)$ \\
\hline \multirow[t]{2}{*}{ Gender } & Male & 14 & 9 & 10 \\
\hline & Female & 90 & 27 & 11 \\
\hline \multirow[t]{5}{*}{ Age group } & $18-24$ & 1 & Not asked & Not asked \\
\hline & $25-34$ & 37 & & \\
\hline & $35-44$ & 34 & & \\
\hline & $45-54$ & 28 & & \\
\hline & $55-64$ & 4 & & \\
\hline \multirow[t]{6}{*}{ Agenda for Change Banding (Career level) } & Band 5 & 5 & Not asked & Not asked \\
\hline & Band 6 & 39 & & \\
\hline & Band 7 & 34 & & \\
\hline & Band $8 a$ & 11 & & \\
\hline & Band $8 b$ & 5 & & \\
\hline & Band $8 \mathrm{c}$ & 10 & & \\
\hline \multirow[t]{5}{*}{ Start year of the Internship Programme } & 2014 & 10 & 8 & Not asked \\
\hline & 2015 & 12 & 11 & \\
\hline & 2016 & 34 & 15 & \\
\hline & 2017 & 48 & 18 & \\
\hline & 2018 & $\mathrm{n} / \mathrm{a}$ & 21 & \\
\hline \multirow{8}{*}{$\begin{array}{l}\text { What is your highest qualification (at entry for the } \\
\text { interns) }\end{array}$} & Diploma & 5 & 0 & 1 \\
\hline & Pre-registration BSC & 53 & 0 & 3 \\
\hline & PgCert or PgDip & 14 & 0 & 1 \\
\hline & Clinical MSC & 13 & 2 & 3 \\
\hline & Pre-registration MSC & 3 & 0 & 0 \\
\hline & Research Masters $^{a}$ & 16 & 5 & 2 \\
\hline & $\mathrm{PhD}$ & 0 & 28 & 2 \\
\hline & Other & 0 & 2 & 0 \\
\hline \multirow[t]{5}{*}{ What area do you work in? } & $\begin{array}{l}\text { Primary and community } \\
\text { care }\end{array}$ & 33 & 4 & 3 \\
\hline & Secondary care & 56 & 7 & 7 \\
\hline & Tertiary care & 11 & 2 & 1 \\
\hline & University & 4 & 22 & 1 \\
\hline & Other & 0 & 1 & 0 \\
\hline \multirow[t]{3}{*}{ How many interns have your supported } & 1 & Not asked & 17 & 7 \\
\hline & 2 & & 3 & 2 \\
\hline & 3 or more & & 16 & 3 \\
\hline
\end{tabular}

Regardless of these perceived inequities, survey respondents were extremely positive regarding the content and delivery of the Internship programmes, though some Interns found the self-directed nature of some programmes challenging. Programmes were largely well- structured with enthusiastic course staff and the outcomes generally met or surpassed their expectations.

The support of the manager and the mentor-intern relationship has the most positive influences on the programme experience, with the main barriers to 
Table 3 The Kirkpatrick Training Evaluation Model used as a framework for the Health Education England/National Institute for Health Research Internship evaluation findings

\begin{tabular}{|c|c|c|c|c|}
\hline Level & $\begin{array}{l}\text { Kirkpatrick } \\
\text { model } \\
\text { focus }\end{array}$ & Kirkpatrick model question & $\begin{array}{l}\text { Internship evaluation } \\
\text { focus }\end{array}$ & Potential topics \\
\hline 1 & Reaction & $\begin{array}{l}\text { To what degree participants react favourably to the } \\
\text { learning event }\end{array}$ & $\begin{array}{l}\text { Stakeholder experiences of } \\
\text { the programme }\end{array}$ & Recruitment and programme experiences \\
\hline 2 & Learning & $\begin{array}{l}\text { To what degree participants acquire the intended } \\
\text { knowledge, skills and attitudes based on their } \\
\text { participation in the learning event }\end{array}$ & $\begin{array}{l}\text { Programme outcomes: } \\
\text { impact on the individual } \\
\text { intern }\end{array}$ & $\begin{array}{l}\text { Completion rates; changes to intern's } \\
\text { knowledge, skills and attributes (e.g. } \\
\text { confidence) }\end{array}$ \\
\hline 3 & Behaviour & $\begin{array}{l}\text { To what degree participants apply what they } \\
\text { learned during training when they are back on the } \\
\text { job }\end{array}$ & $\begin{array}{l}\text { Learning transferred and } \\
\text { applied into clinical practice }\end{array}$ & $\begin{array}{l}\text { Impact beyond self to others (e.g. research } \\
\text { champion, research culture) }\end{array}$ \\
\hline 4 & Results & $\begin{array}{l}\text { To what degree the targeted outcome occurs, as a } \\
\text { result of the learning event(s) and their subsequent } \\
\text { reinforcement }\end{array}$ & $\begin{array}{l}\text { Research career progression } \\
\text { and impact within an } \\
\text { organisational context }\end{array}$ & $\begin{array}{l}\text { Progression to Integrated Clinical Academic } \\
\text { pathway and roles; other indicators of } \\
\text { research career progression }\end{array}$ \\
\hline
\end{tabular}

clinical academic activity as perceived by survey respondents being the lack of time $(27.8 \%, n=29)$ with some instances of poor line manager support $(20.2 \%$, $n=21)$.

"...other clear enablers are having the time, and I struggled a little bit with that, because I ended up doing most of it outside of my working week...and most of it I did in my own time. And I'm not saying that would stop me doing stuff. It wouldn't, but at the end it's a bit of a kick in the teeth ... Because even if someone buys your time, they're actually paying the organisation, and you've still got to make that time." (Mentor 4)

"You have to really have that support and buy-in from your line manager...and certainly amongst those [interns] they didn't always have their line manager's support...it's almost like it's Everest before they've even got onto the course." (Line Manager 6)

Utilising funding for releasing both intern and mentor time (backfill) was consistently cited as a challenge in both the survey and the interviews, although some managers suspected backfill was easier in other professions:

"I think probably another barrier, and this is quite unique to our profession, is that unlike nursing [where] you've got quite a big pool of bank nurses that you can just dip into for a shift. It doesn't really work like that for therapists..." (Line Manager 6)

"I think for many clinical managers, and particularly for nursing where there's such a shortage of nurses in practice, I think sometimes it's not that the managers don't want to support these things, it's they

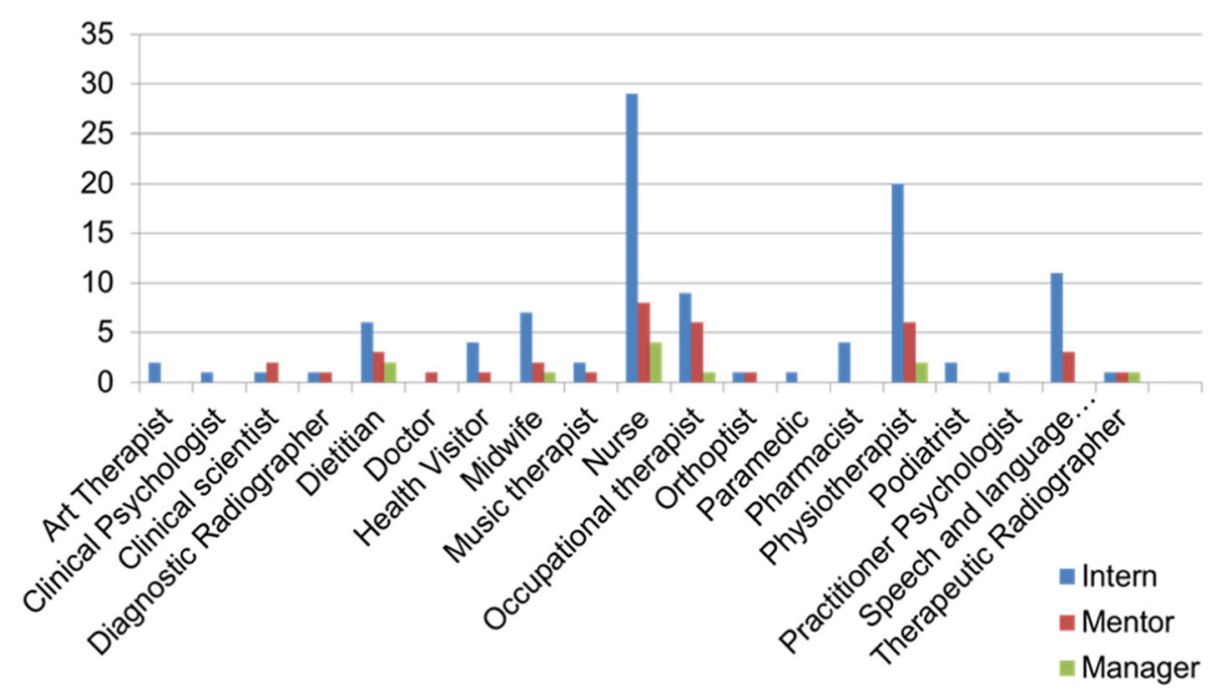

Fig. 1 Registered professional groups of survey respondents 
can't because they just don't have anybody available [for backfill]." (Mentor 2)

"I would say we had underestimated the real pull of the day job here, that we're here to deliver the clinical service. That even if you've got the backfill ... it is actually really difficult to practically put into place..." (Line Manager 6)

Backfill funding varied substantially between regions. Interns on part time contracts were paid additional time to undertake the programme by increasing their hours, though this was not available to full-time employees. However, creative use of funding was discussed by one manager as an alternative to standard backfill:

"What we did is that the money that we got in we were able to utilise for further study and study days for her other team members, and for courses that we never would have been able to have funded ourselves. So [the intern], she felt great, because she was able to do it, there wasn't this pressure that she felt she was leaving her colleagues 'in the lurch'. And her colleagues felt that they were getting something from it as well." (Line Manager 6)

Enablers for success on the programme are multifactorial, with interns and mentors reiterating the importance of the supervisory relationship. Mentors identified challenges of supporting Interns with an unclear research focus, and time and funding limitations. The importance of an internship that is intern rather than mentor driven was expressed by $86 \%$ mentors and $52 \%$ of interns.

\section{Level 2 analysis - learning (programme outcomes and} impact on the individual)

All responding interns had successfully completed their internship programme (100\% completion). Following completion, the graduate interns valued their new research skills and knowledge and the opportunity to engage in research and research networks. The internship had a high impact upon their confidence, patient care and their role, with a lesser perceived impact on their department and their colleagues. Conversely, 92\% of managers recognised positive impacts upon the department, the interns' colleagues and patient care; $75 \%$ also recognised positive impacts upon role and skills:

"I would also say positively that I feel that it's changed their clinical practice in terms of the fact that although we're a graduate profession...it just seems to give them that next step, or that next way of thinking..." (Line Manager 6)
Only a third of the line managers had been involved in project selection; however, $83 \%$ identified that the project had been embedded in the department. While there were mixed views regarding the balance of the clinical and academic components, and the impact on self, nevertheless, all recognised the impact of 'thinking time' that the internship had afforded:

"I think it's an ideal programme and it's very good for the individual. But I really don't think there's much linkage with clinical practice. It's very academic. The academic is very separate from the clinical practice, and trying to link the two together, it doesn't really happen. It does seem to run in a very separate environment." (Mentor 2)

"It is a really important time out for people wanting to progress a clinical academic pathway to really have that thinking time to hone their ideas...that was really beneficial." (Intern 3)

\section{Level 3 analysis - behaviour (learning applied into clinical practice)}

Expectations of managers was that the Internship would ideally have a positive impact on patient care but also on other colleagues, a so-called 'ripple effect'.

"So for me as a service manager I needed to ensure that this was something that would improve patient care ultimately..." (Line Manager 1)

"I the line manager hadn't appreciated the positive... impact that it was going to have on the wider department. And that certainly is something that has now rippled through the rest of the department" (Line Manager 6)

While NMC-registered interns in the survey had identified greater positive outcomes related to individual roles, skills and confidence, HCPC-registered interns reported having a greater impact on the wider department. Both mentors and interns in the interviews also recognised their impact on their colleagues and saw the intern as a driver for change:

"I also hoped that it would contribute to improve her overall confidence, and have an impact on the wider team..." (Mentor 2)

"I think the internship definitely started to charge organisational attitude to clinical academic opportunities...So taking on the first one and being a role model ... I think that's a privilege..." (Intern 3) 
Stakeholder expectations are not always aligned regarding progression beyond the internship, with some arguing that a longer-term impact on clinical practice could only be achieved if the internship was seen as the start of a research career journey, not the end-point:

"My expectations as a mentor were that I would be able to take my [intern] right the way through their programme... so that they didn't just stop at the end of the [internship]. That was I felt fairly clear that it wasn't just about this being a one-off internship... It was more about their onward journey as a clinical academic, if that's what they want to be..." (Mentor 4)

Conversely, the majority of respondents see the Internship as a valuable early career 'research taster' and personal development opportunity; unlike the quotation above, a decision not to continue is acknowledged by some as an acceptable and indeed successful outcome.

"It's great to see these internships give people a real chance to understand what early career research looks like, what it is, how it differs from ordinary service development or clinical audits. And it gives them a protected time in which to assess whether or not it is a long-term career for them... And there is no expectation that you continue on that pathway after it, so it's a taster really that we couldn't afford to offer without the internship." (Line Manager 1)

"So while it is absolutely being supportive of those people, I think we've got that duty as line managers of also identifying those staff that it's not the right time for them to be doing it." (Mentor 6)

"It helps you to understand really quite well what a clinical academic career might look like. And gives you time and space to think that through and decide whether that's the right path for you. I didn't feel any pressure at the end of it to continue in that direction but I felt like I had a lot more ability to make decisions about that." (Intern 7)

\section{Level 4 analysis - results (progression and impact in an organisational context)}

In the United Kingdom, registered nurses, midwives and allied health professionals working clinically within the NHS occupy Agenda for Change pay bandings from Band 5 (early career) up to Band 8 (senior level/consultant practice). The majority of interns occupy Bands 6 and 7; only 19 interns (18.2\%) reported progression to a higher pay band since completing the internship (Fig. 2). However, a greater proportion of interns $(40 \%)$ reported changes in role titles that reflected career progression. There was no specific difference in enhancement of roles between professional groups.

Post-internship, $52 \%$ had applied for a higher stage of the HEE/NIHR ICA pathway (Table 4). While the percentage of interns applying from NMC and HCPC backgrounds were similar, more HCPC-registered interns applied for NIHR doctoral level study. Of the $52 \%$ of interns who applied, 50\% were successful (some were awaiting the outcome of their applications). Interns registered with HCPC had higher success rates than NMCregistered interns (50\% compared to $42 \%$ ).

Applications to these ICA pathway awards are more likely (and more likely to be successful) from those in the 45+ age band, occupying Agenda for Change Band 7 roles, and who have completed post-registration Masters degrees. The ICA research pathway is not the only funding stream to which graduate interns applied to support the next stages of their clinical academic career; good success rates were evidenced for other funding streams (Table 5).

Overall, $48 \%$ of interns had not applied for the next stage of the ICA research pathway. Middle managers were identified by both interns and mentors as gatekeepers; managers were sometimes reluctant to support ICA progression, preferring instead to support further intern applications within their team. Release from work,

\begin{tabular}{|c|c|c|c|c|c|c|c|}
\hline \multicolumn{8}{|c|}{ Pay band progressed to $\longrightarrow$} \\
\hline \multirow{7}{*}{ 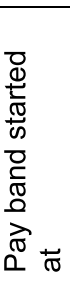 } & & Band 5 & Band 6 & Band 7 & $\begin{array}{l}\text { Band } \\
8 a\end{array}$ & $\begin{array}{l}\text { Band } \\
8 b\end{array}$ & Other \\
\hline & Band 5 & 5 & 3 & 2 & 0 & 0 & 1 \\
\hline & Band 6 & 0 & 35 & 8 & 0 & 0 & 2 \\
\hline & Band 7 & 0 & 0 & 24 & 4 & 0 & 1 \\
\hline & Band $8 a$ & 0 & 1 & 0 & 7 & 2 & 1 \\
\hline & Band $8 b$ & 0 & 0 & 0 & 0 & 3 & 1 \\
\hline & Other & 0 & 0 & 0 & 0 & 0 & 4 \\
\hline
\end{tabular}

Fig. 2 Pay band progression from start of Internship until survey completion 
Table 4 Number of interns who had applied for a further programme on the ICA Pathway

\begin{tabular}{lllll}
\hline ICA Level applied for & All interns completing $(\boldsymbol{N}=\mathbf{1 0 0})$ & NMC $(\boldsymbol{N}=\mathbf{4 0})$ & HCPC $(\boldsymbol{N}=\mathbf{5 9})$ & Other $(\boldsymbol{N}=\mathbf{5})$ \\
\hline ICA MRes & $27(27 \%)$ & 10 & 15 & 2 \\
ICA PCAF & $8(8 \%)$ & 3 & 5 & 0 \\
ICA Doctorate & $13(13 \%)$ & $3(8 \%)$ & $11(19 \%)$ & 0 \\
ICA Post-Doctorate & 0 & 0 & 1 & 0 \\
Other & $4(4 \%)$ & 3 & $32(54 \%)$ & 2 \\
Application to any higher level of NIHR ICA pathway & $52(52 \%)$ & $8(42 \%)$ & $16(50 \%)$ & $2(100 \%)$ \\
Of those applications, no. of successful awards & $26(50 \%)$ & & 0 \\
\hline
\end{tabular}

HCPC Health and Care Professions Council, ICA Integrated Clinical Academic, NIHR National Institute for Health Research, NMC Nursing and Midwifery Council, PCAF Pre-doctoral Clinical Academic Fellowship

lack of funding and a shortage of ICA pathway places were also noted by interns as major barriers to progression (Figure 3).

A total of $19 \%$ of mentors expressed concerns regarding a widening skills gap between Internship completion and a successful application for the next step on the ICA research career ladder (PCAF). For some interns and mentors this was seen as an insurmountable gulf, which effectively ended their research career progression aspirations. For others, the highly competitive nature of the PCAF application process necessitated further research activity and/or bridging programmes to strengthen their applications. Access to mentors following the Internship was seen as vital for successful progression; while lack of funding may be a barrier to supervision beyond the internship, $56 \%$ of mentors said they would support the interns even if they were not paid.

"And you start this process and you have some good outcomes, and you want to continue [to PCAF]. But then you come away slightly disillusioned...Because along the way you're just given lots of messages of how competitive it is..." (Intern 4)

"So my expectations were that it was quite a seamless process. So you could start as being an intern, then progress onto PCAF, and then spend some time and apply for an NIHR grant for a doctorate. So those were my expectations. Having now completed the internship the reality is that the PCAF is a very competitive process, and one would need to complete lots of other activities to build up research experience." (Intern 5)

Many Interns commented on the challenges posed by a lack of a defined research career structure and role models that they could aspire to; most do not see how a clinical-academic framework could become a reality in their department or professional group.

"... they were talking about their own careers as a clinical academic...all of them spoke of the difficult time, and how you have to be so driven.... how they felt that due to the framework not being there...... there's no formal structure in place in how to be a clinical academic." (Intern 5)

"...you kind of get a lot of investment in you and then not much at the end...I can't find the system to support me." (Intern 8)

Despite these challenges, success appears to breed success. Departments who supported previous Interns are more likely to apply for and be successful in future applications. Support for departments new to research is vital for the ICA programme to be embraced:

Table 5 Numbers of interns applying for professional body and charitable funding

\begin{tabular}{|c|c|c|c|c|c|}
\hline & Total applying & Total successful & $\begin{array}{l}\text { NMC success } \\
(N=11)\end{array}$ & $\begin{array}{l}\text { HCPC success } \\
(N=14)\end{array}$ & $\begin{array}{l}\text { Other success } \\
(N=0)\end{array}$ \\
\hline Professional body and charitable research funding ${ }^{a}$ & 24 & $18(71 \%)$ & 7 & 11 & \\
\hline Other career pathway funding ${ }^{b}$ & 21 & $11(52 \%)$ & 3 & 7 & 1 \\
\hline
\end{tabular}

axamples: Royal College of Nursing PhD funding, Pharmacy Research United Kingdom Training Bursary, Chartered Society of Physiotherapy Charitable Trust; bxamples: CLAHRCs (Collaborations for Leadership in Applied Health Research and Care), National Institute for Health Research Contingency funding, Health Education England-funded bridging programmes and employer-funded MRes HCPC Health and Care Professions Council, NMC Nursing and Midwifery Council 

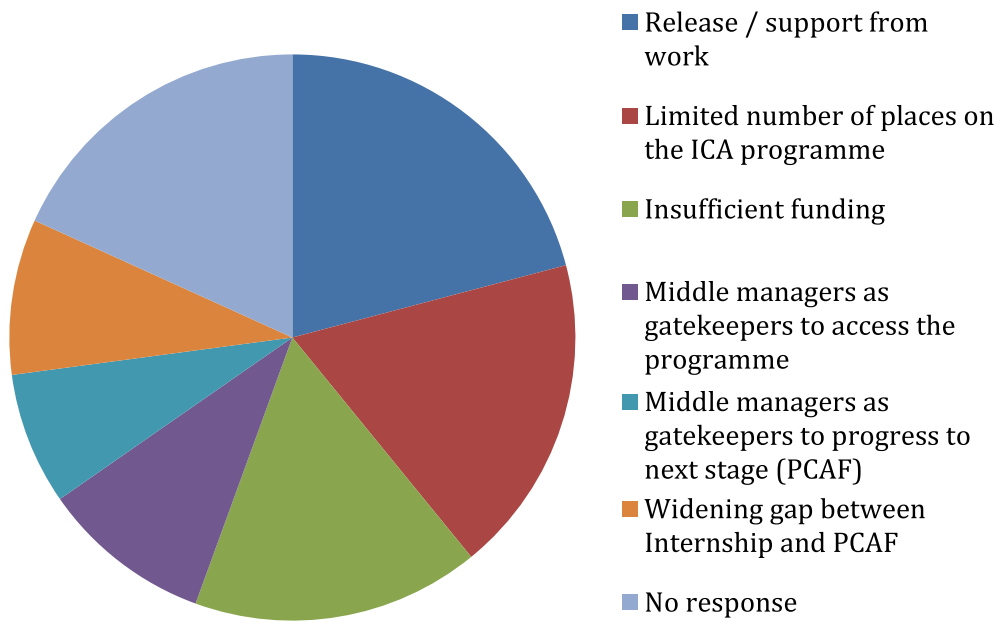

No response

Fig. 3 Intern reported barriers to progressing to the next stage of the ICA programme

\begin{abstract}
"And I think very early on, because we didn't have the bigger oversight of what the internship leads to in the organisation...it was just quite a low level thing; whereas now we're promoting internships and pre-doctoral fellowship opportunities and we can now demonstrate to people what the pathway looks like and where our ambition lies." (Intern 3)
\end{abstract}

\section{Discussion}

A mixed-methods approach was employed to evaluate the short- to medium-term impacts of the 10 HEE/NIHR Internship programmes across England. The discussion will be embedded within the fourlevel framework of the New World Kirkpatrick model [41].

\section{Stakeholder experiences of the internship}

At Level 1 (reaction), intern experiences once enrolled upon the programmes are overwhelmingly positive, as identified in previous studies [17, 30-33]; outcomes generally met or surpassed their expectations. However, the competition for places was strong and many respondents highlighted variability in admissions policies, with Masters' degrees viewed as either an advantage or a barrier to entry. Regional influences inadvertently created different internship models, yet applicants were unable to 'cross borders' to access the model of their choice. While nurses are well represented in this study, the numbers are small in comparison to the size of their profession. Some AHP groups are well represented (Physiotherapy, Speech and Language Therapy and Dietetics), yet others have limited or no representation as indicated by Hiley et al. in their evaluation of the West
Midlands clinical academic careers programme [15]. This unrepresentative professional landscape was, according to some stakeholders, exacerbated by ineffective cascading across large organisations, also recognised by Dimova et al. as a barrier to NHS research [47]. Even where organisations spread positive messages about research, the line managers were consistently recognised as the 'gatekeepers' to accessing the programme. Service and ward-based professions may have significantly more barriers to engagement in research due to routine operational pressures in addition to national workforce shortages in some professions such as diagnostic radiography [48, 49]. In addition, relatively recent transitions to degree entry present additional challenges for some professions such as operating department practitioners and paramedics. By engaging with the Internship, AHP professions have potential to add value to their services by promoting evidence-based practice initiatives; this increases professional recognition, enables them to exercise greater autonomy, and to profile research within their professional work plans. Conversely, for those groups who remain unrepresented, the transfer and knowledge exchange has not yet been realised; engaging with these underrepresented groups will be important in ensuring that the potential impact of the Internship programme reaches across all services, wards and patient pathways.

Within the Level 2 (learning) analysis, 100\% of the interns engaging with this study successfully completed their internship programme, unlike some previous studies which report variable completion rates [29]. Learning environments within the different programmes either delivered a research taster, a career 
escalator through the NIHR research pathway or a combination of the two. This fuelled multiple stakeholder perspectives on the primary purpose of the internship, with success meaning different things to different stakeholders with consequent mixed messages.

Level 3 (behaviour) analysis identified that the mentor-intern relationship has the most positive influences on the programme experience. Barriers to clinical academic activity included lack of time and some instances of poor line manager support. Some Interns were unable to use the opportunity due to ineffective backfill practices; managers also highlighted significant challenges in using backfill funding to release time for full-time employees. In contrast, Interns on part-time contracts had more flexibility; this funding system appears to selectively penalise full time employees who are already at full capacity.

The analysis for Level 4 (results) showcased the outcomes of the programme from the perspectives of all stakeholders. Interns described their learning as gradually becoming 'research active'. Positive impacts upon the interns (increased confidence, enhanced patient care and more fulfilled roles) were recognised extensively by all stakeholder groups; these impacts are noted in other studies [9, 16-18, 30, 33-39]. Wider impacts include enhanced research culture within their teams, the so-called 'ripple effect' identified by other researchers [50], and a more evidencebased approach to professional practices. Given these impacts, it is unsurprising that clinical academics are often seen as the gatekeepers for the dissemination of information by translating research into clinical practice [8-13].

\section{Progression beyond the internship}

Progression through and beyond the internship appears to be dependent on the readiness of the leadership and management in the organisational context to accept and support clinical academic progression as a legitimate and embedded professional activity. Just over one-quarter of intern respondents in this study had successfully applied for the next stage of the NIHR ICA pathway; progression was more likely from those in the 45+ age band, occupying Agenda for Change Band 7 roles, and who had completed post-registration Masters degrees. A report by the Associates of United Kingdom University Hospitals generated a target of $1 \%$ of NMAHPS in clinical academic roles by 2030 [20]; while these successful transitions are welcomed, it is concerning that $43 \%$ of the Interns surveyed had not applied for the next stage of their ICA development. Cooke et al. had argued that the $1 \%$ target was unlikely to be achieved [21] in the absence of sufficient available funded places. Respondents concurred that competition for places was high and viewed as 'insurmountable' by some; additional barriers to progression included the absence of research career frameworks, role models and clinical academic recruitment opportunities. Clinical academic posts are indeed rarely advertised [27] and are often held at pay scales that respondents suggest do not reflect the level of responsibility of the role, a trend noted both nationally and internationally $[17,30,34,36]$. Since completion of the higher level ICA doctoral fellowship programmes, many award recipients had transitioned to an academic position or a clinical post (with no formal sessions for research) [14]. Disappointingly, many returned to the role they held pre-fellowship [14], a worrying indictment for the future of clinical academia.

ICA pathway progression is not the only route to a clinical academic career, with many interns applying for alternative sources of research funding. Career progression was also evident for many interns, achieving a higher pay band and/or enhanced role titles. Clearly evident is the desire and drive shown by many interns to progress their careers yet, for many, the ICA pathway appeared not to be the mechanism to facilitate this. In their evaluation of the West Midlands clinical academic career programme, Hiley et al. described a mentorship gap between the end of intern programmes and submission of publications or next-stage funding applications [15]. This finding was confirmed, with the absence of mentorship and funding to support the transition journey seen as a significant barrier to progression, given the high degree of preparation required for a successful PCAF application. Lack of financial support during and post completion of internships is seen as a fundamental barrier to progression in several other international studies [17, 18, 33, 36]. This transitionary mentorship support, provided currently outside of the funded programmes, relies on goodwill and commitment of senior people who may already have taken on new interns and are therefore at capacity. Mentorship capacity will continue to be a challenge in the foreseeable future as allied health active researchers in practice are low [27], occupying less than $0.1 \%$ of the workforce [20].

\section{Addressing the research skills gap}

Significant changes are required at national, professional, institutional and middle management levels to address this research skills gap. Alternative 
approaches to the HEE/NIHR model provide interesting contrasts; for example, the Victorian Government in Australia have invested in AHP research as an essential component of practice development [51], underpinning evidence-based, person-centred practice. Strategic investment in joint posts within 10 health and care organisations ensures that the 'clinical academic' will drive quality and safety improvements in practice. This model contrasts with the NIHR model of individual career development as a mechanism for releasing workforce capacity for research. The Victorian allied health research framework, informed through a systematic review of the literature [22], provides a platform from which research capacity-building strategies can be developed across organisations.

Organisations and managers need to be challenged to commit organisational support to those who are prepared to develop clinical academic careers and this requires investment in the clinical/professional service. Research activity undertaken by clinical academic practitioners needs to be strategically planned in relation to required impacts in quality and service improvement. This 'payback' [52], in relation to service outcomes and patient benefits in practice, allows clinical academics to demonstrate a contribution to the population health management at systems level. Within the United Kingdom, the inclusion of research within national Care Quality Commission inspections [53] anecdotally appears to be providing a clearer incentive and narrative for healthcare managers to support their staff to engage in research. This will take time to embed across all institutions and departments; consequently, the pursuit of a clinical-academic career will continue to be elusive for many in the absence of a defined research career structure and visible and proactive role models for all NMAHP.

\section{Limitations}

The survey population included all interns registered on programmes from 2014 to 2018. During this time, a number of changes to the ICA pathway were adopted, in addition to changes to HEE regional boundaries and to programme providers within regions. These changes have all impacted upon the complexity and reliability of data collection and analysis; directly comparing annual cohorts was not feasible.

The invitations to participate in the survey were based on limited and incomplete datasets from 10 different regional programmes; many contact emails supplied to the research team were returned automatically as 'undeliverable'. While we do not anticipate that this impacted upon the overall survey results, the small numbers in some sub-groups mean that we are unable to draw conclusions about any individual professions or regional programmes. The line manager response was lower than expected and so our data may not be fully representative. While the intern responses were high $(n=104)$, we estimate that this is likely to represent $25 \%$ of the total number of Internship registrations nationally, which is not unusual for an online survey applied retrospectively to completed cohorts. It is acknowledged that the interviews did not achieve saturation but were used to offer depth of insight to illuminate many of the survey findings.

\section{Conclusion}

The internship programme is highly valued and has a positive impact upon interns' confidence, patient care and their workplace. It is evident, however, that many challenges persist in enabling NMAHPs to engage with activities that develop research capacity, even within a well-funded supportive programme such as the HEE/NIHR Internship. In particular, the service provision challenges facing middle management creates barriers to Internship recruitment, effective back-fill and progression beyond the Internship. This facilitation appears to be particularly challenging in small professional groups and in larger service-orientated departments.

The current Internship programme succeeds in providing a range of important early experiences in research, though progression beyond the programme is challenging. A widening gap between Internship and the next level of the ICA framework has been highlighted, with vital mentorship support to bridge this gap threatened by a lack of time and funding. The Internship is the entry-level programme for the ICA career escalator, a model designed to facilitate individual research career development. However, alternative approaches that drive nursing and allied health research development within and between organisations, such as the Victorian model, may support inclusion of a wider range of professions and enhanced progression opportunities. While national Care Quality Commission inspections may provide a clearer research narrative to encourage managers to support their staff to engage in research, the pursuit of a clinical-academic career will continue to be elusive for many NMAHP. Further research is required to explore the longer-term impacts of the Internship on research career progression, including whether clinicians remain in a clinical academic or research related role, and the support they require to do so. 


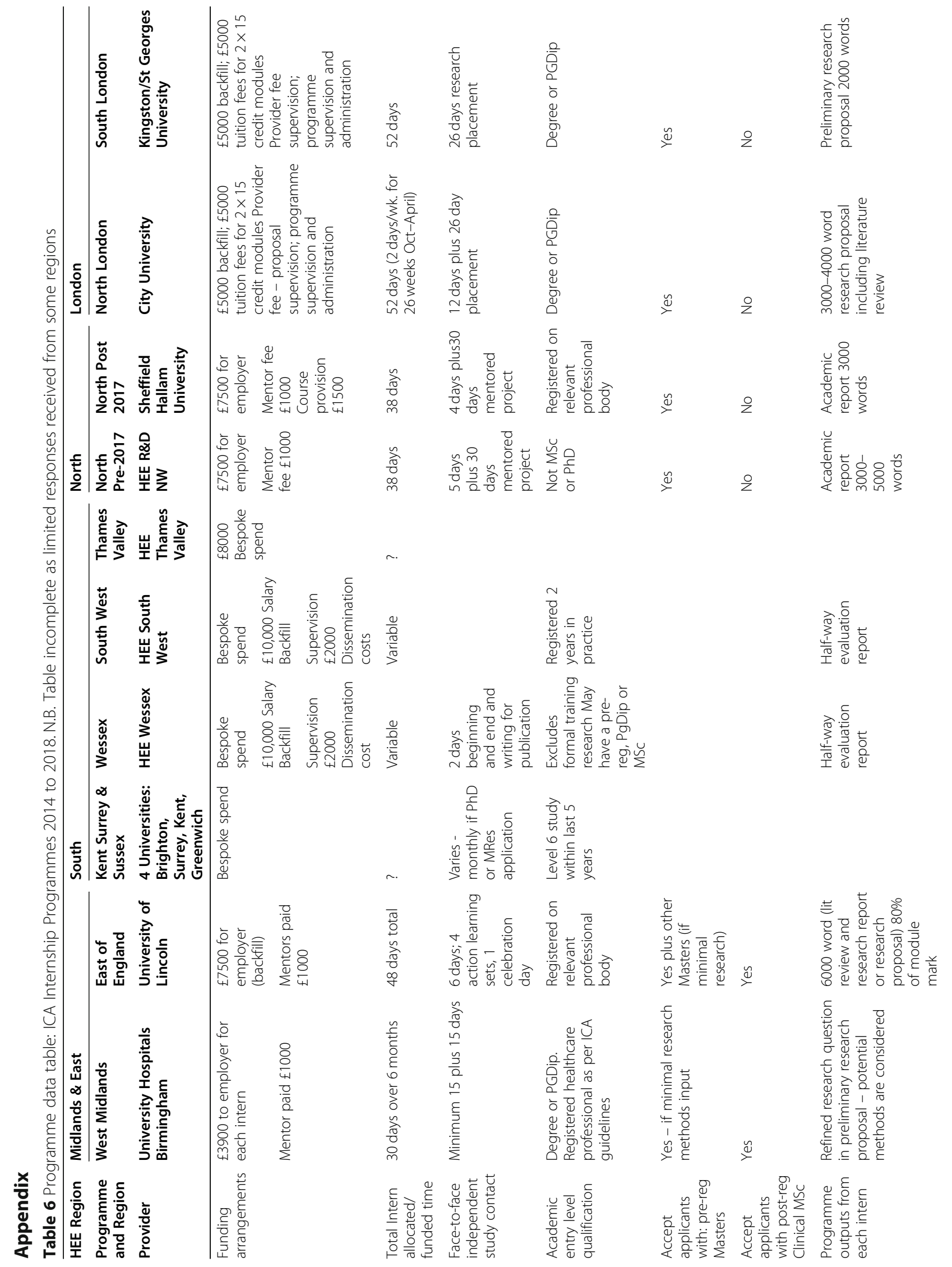




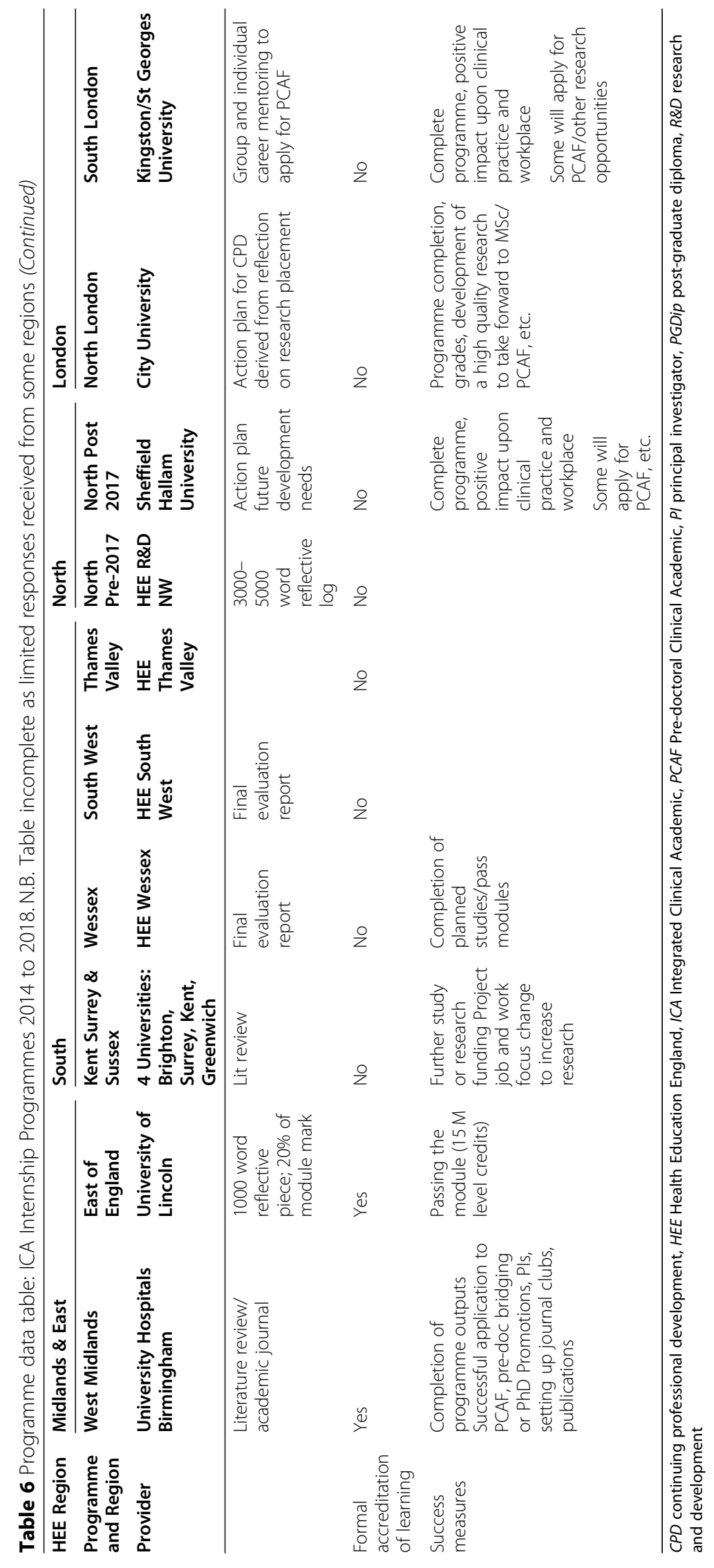




\section{Abbreviations}

AHP: Allied Health Professions; HCPC : Health and Care Professions Council; HEE : Health Education England; ICA : Integrated Clinical Academic; NHS: National Health Service; NIHR : National Institute for Health Research; NMAHP : nursing, midwifery and allied health professions; NMC : Nursing and Midwifery Council; PCAF : Pre-doctoral Clinical Academic Fellowship

\section{Acknowledgements}

We wish to thank all participating Education Providers, graduate interns, their managers and their supervisors who took part in the study.

\section{Authors' contributions}

PI for the study and lead for study design - JN, KG. Ethics requests and approvals - JN. Literature review: DH, CL. Design of data collection tools: All authors. Focus group data collection and analysis: JN, KG. Survey Data collection and analysis: SK, CL. Interview data collection and analysis: RL, BB, JN. Framework analysis: JN, SFD. Preparation of final manuscript: JN, SFD. All authors read and approved the final manuscript.

\section{Authors' information}

Not applicable.

\section{Funding}

This study was funded by Health Education England (HEE). HEE are the funders of the internship programme that was being evaluated. HEE had no part in the design of the study and data collection, analysis, and interpretation of data and in writing the manuscript. However, they supplied contact details of providers and gatekeeper access to request contact emails for the survey.

\section{Availability of data and materials}

The survey and interview datasets used and/or analysed during the current study are available from the corresponding author on reasonable request.

\section{Ethics approval and consent to participate}

The project was submitted to Sheffield Hallam University Research Ethics Committee in two stages for ethical approval (Ethics ID: ER10500858; ER12442076). Gatekeeper access was also granted from Health Education England (funder of the internship programmes). Participant information leaflets and consent forms were developed and all responses were anonymised; participants were assured of confidentiality and right to withdraw until completion of data analysis.

\section{Consent for publication}

Not applicable.

\section{Competing interests}

Sheffield Hallam University currently delivers one of the 10 regional Internship programmes funded by Health Education England, and the first author is the programme lead.

\section{Author details}

'Department of Allied Health Professions, Sheffield Hallam University, Sheffield, UK. ${ }^{2}$ University of Lincoln, Lincoln, UK. ${ }^{3}$ University of Sheffield, Sheffield, UK. ${ }^{4}$ Manchester University NHS Foundation Trust, Manchester, UK.

Received: 27 May 2020 Accepted: 29 September 2020

Published online: 19 October 2020

\section{References}

1. National Institute for Health Research. Link to Internship eligible professions: https://www.nihr.ac.uk/documents/heenihr-ica-programme-eligibleprofessions-and-regulators/12204 Accessed 23 Apr 2020.

2. Wenke RJ, Ward EC, Hickman I, Hulcombe J, Phillips R, Mickan S. Allied health research positions: a qualitative evaluation of their impact. Health Res Policy Syst. 2017;15:6

3. Cooke J, Gardois P, Booth A. Uncovering the mechanisms of research capacity development in health and social care: a realist synthesis. Health Res Policy Syst. 2018;16:93. https://doi.org/10.1186/s12961-018-0363-4.

4. Faden RR, Kass NE, Goodman SN, Pronovost P, Tunis S, Beauchamp TL. An ethics framework for a learning health care system: a departure from traditional research ethics and clinical ethics. Hast Cent Rep. 2013;43(s1): S16-27. https://doi.org/10.1002/hast.134.

5. NIHR Trainees Coordinating Centre. Ten Years On: Adapting and Evolving to New Challenges in Developing Tomorrow's Health Research Leaders. July 2017. https://www.nihr.ac.uk/documents/explore-nihr/academyprogrammes/NIHR\%20Strategic\%20Review\%20of\%20Training\%202017.pdf. Accessed 24 May 2020

6. Trusson D, Rowley E, Bramley L. A mixed-methods study of challenges and benefits of clinical academic careers for nurses, midwives and allied health professionals. BMJ Open. 2019;9(10):e030595. https://doi.org/10.1136/ bmjopen-2019-030595.

7. Tricco AC, Lillie E, Zarin W, O'Brien K, Colquhoun H, Kastner M, et al. A scoping review on the conduct and reporting of scoping reviews. BMC Med Research Methodol. 2016;16:15. https://doi.org/10.1186/ s12874-016-0116-4.

8. Watson N, Tang P, Knight E. Survey of medical clinical academic staffing levels 2018. 2018. https://www.medschools.ac.uk/media/2491/msc-clinicalacademic-survey-report-2018.pdf. Accessed 15 Feb 2019.

9. Westwood G, Richardson A, Latter S, Macleod Clark J, Fader M. Building clinical academic leadership capacity: Sustainability through partnership. J Res Nurs. 2018;23(4):346-57.

10. Health Education England. Research and innovation strategy: Developing a flexible workforce that embraces research and innovation. 2015. https:// www.hee.nhs.uk/sites/default/files/documents/HEE\%20research\%20and\%2 Oinnovation\%20strategy.pdf. Accessed 10 Feb 2019.

11. Health Education England/National Institute of Health Research. ICA programme for non-medical healthcare professions. 2015. https://www.nihr. ac.uk/our-research-community/NIHR-academy/nihr-training-programmes/ nihr-hee-ica-programme/0918\%20_\%20ICA_BOOKLET_GUIDE_FINAL.pdf. Accessed 9 Feb 2019

12. Kennedy R, Beasley C, Bradley M, Moore R.. Midwifery 2020: Delivering expectations. 2020. https://assets.publishing.service.gov.uk/government/ uploads/system/uploads/attachment_data/file/216029/dh_119470.pdf.

13. Prime Minister's Commission. Front line care report by the on the future of Nursing and Midwifery in England 2010. https://webarchive.nationalarchives. gov.uk/20100331110913/http://cnm.independent.gov.uk/wp-content/ uploads/2010/03/front_line_care.pdf. Accessed 9 Feb 2019.

14. Richardson A, Avery M, Westwood G. A Cross-Funder Survey of Enablers and Barriers to Progressing a Research-Related Academic Career in the Non-Medical Health Professions. Report to Health Education England, 2019. https://www.southampton.ac.uk/ healthsciences/about/staff/ar2y08.page.

15. Hiley J, Begg C, Banks L, Harper L, Swift A, Topping A. West midlands clinical academic careers programmes for nurses, midwives, allied health professions, pharmacists and healthcare scientists (NMAHPPS) evaluation report. 2018. https://www.birminghamhealthpartners.co.uk/wp-content/ uploads/2018/11/West-Mids-Clinical-Academic-Careers-ProgrammesEvaluation-Report-Oct-2018-4.pdf. Accessed 9 Feb 2019.

16. Clark L, Casey D, Morris S. The value of master's degrees for registered nurses. Br J Nurs. 2015;24(6):328-34.

17. Brayer A, Marcinowicz L. Job satisfaction of nurses with master of nursing degrees in Poland: Quantitative and qualitative analysis. BMC Health Serv Res. 2018;18:239.

18. Cobbing S, Maddocks S, Govender S, Khan S, Mbhele M, Naidoo K, et al. Physiotherapy postgraduate studies in South Africa: Facilitators and barriers. South Afr J Physiotherapy. 2017;73(1):335.

19. Palmer J. Australian bureau of statistics annual report 2013-14. 2014 http://www.ausstats.abs.gov.au/Ausstats/subscriber.nsf/0/0BCB69DE78266 7DACA257D7200114E5D/\$File/abs_annual_report_2013_14_web.pdf. Accessed 11 Feb 2019.

20. Association of UK University Hospitals. National Clinical Academic Roles Development Group for Nurses, Midwives and Allied Health Professionals. 2010. http://www.aukuh.org.uk/index.php/affiliate-groups/nmahps. Accessed 05 May 2020.

21. Cooke J, Bray K, Sriram V. Mapping research capacity activities in the CLAH RC community supporting non-medical professionals executive summary. 2016. https://www.clahrcprojects.co.uk/sites/default/files/uploads/235\%2 OSummary\%20report\%20print.pdf. Accessed 11 Feb 2019.

22. Slade SC, Philip K, Morris ME. Frameworks for embedding a research culture in allied health practice: a rapid review. Health Res Policy Syst. 2018;16:29. https://doi.org/10.1186/s12961-018-0304-2. 
23. Fowler DS. Going for growth: improvement in the infrastructural and management support for clinical academic research. BMJ Open Quality. 2015;4(1):u208144-w3845.

24. Perry L, Grange A, Heyman B, Noble P. Stakeholders perceptions of a research capacity development project for nurses, midwives and allied health professionals. J Nurs Manag. 2008;16:315-26.

25. Pager S, Holden L, Golenko X. Motivators, enablers, and barriers to building allied health research capacity. J Multidiscip Healthc. 2012;5:53-9.

26. Di Bona L, Field B, Read J, Jones N, Fowler Davis S, Cudd P, et al. Weaving a clinical academic career: Illuminating the method and pattern to follow. BJOT. 2019;82(1):60-4.

27. Council of Deans for Health. Nursing, midwifery and allied health clinical academic research careers in the UK. 2018. https:// councilofdeans.org.uk/wp-content/uploads/2018/08/Nursing-midwiferyand-allied-health-clinical-academic-research-careers-in-the-UK.pdf. Accessed 9 Feb 2019

28. Department of Health. Developing the role of the clinical academic researcher in the nursing, midwifery and allied health professions. 2012. https://assets.publishing.service.gov.uk/government/uploads/system/ uploads/attachment_data/file/215124/dh_133094.pdf. Accessed 9 Feb 2019.

29. Landeen J, Kirkpatrick H, Doyle W. The hope research community of practice: Building advanced practice nurses' research capacity. Can J Nurs Res. 2017;29(3):127-36.

30. Bagley K, Hoppe L, Brenner GH, Crawford M, Weir M. Transition to nursing faculty: Exploring the barriers. Teach Learn Nursing. 2018;13(4):263-7.

31. Graue M, Rasmussen B, Iversen AS, Dunning T. Learning transitions-a descriptive study of nurses' experiences during advanced level nursing education. BMC Nurs. 2015;14:30.

32. Lim AG, North N, Shaw J. Experiences of nurses as postgraduate students of pharmacology and therapeutics: A multiple case narrative study. Nurse Educ Today. 2014;34(6):985-90.

33. Stutzman S, Olson D, Supnet C, Harper C, Brown-Cleere S, McCulley B, et al. Promoting bedside nurse-led research through a dedicated neuroscience nursing research fellowship. J Nurs Admin. 2016:46(12):648-53.

34. Abraham PJ, Me Gohan L, Pfrimmer DM. Retaining master and DNP registered nurses in direct patient care: Utilizing nurses to the fullest extent of their education. Nurse Leader. 2015;13(1):70-7.

35. Auerbach DI, Martsolf GR, Pearson ML, Taylor EA, Zaydman M, Muchow AN, et al. The DNP by 2015: A study of the institutional, political, and professional issues that facilitate or impede establishing a post-baccalaureate doctor of nursing practice program. Rand Health Q. 2015;5(1):3.

36. Broussard L, White D. School nurse intention to pursue higher education. J Sch Nurs. 2014;30(5):340-8

37. Duffy SA, McCullagh M, Lee C. Future of advanced practice public health nursing education. J Nurs Educ. 2015;54(2):102-5.

38. Fry M, Dombkins A. Interventions to support and develop clinicianresearcher leadership in one health district. Int J Health Care Qual Assur. 2017;30(6):528-38.

39. Gloster AS, Neville L, Windle J. Effects of advanced practitioners' learning in one hospital. Nurs Manag. 2015;21(10):23-30.

40. Lakhani A, Jan R, Mubeen K, Karimi S, Shahid S, Sewani R, et al. Strengthening the knowledge and skills of community midwives in pakistan through clinical practice internships. J Asian Midwives. 2016;3(2):26-38.

41. Kirkpatrick JD, Kirkpatrick WK. Kirkpatrick's four levels of training evaluation. Alexandria, VA: ATD Press; 2016.

42. Rajeev P, Madan MS, Jayarajan K. Revisiting Kirkpatrick's model-an evaluation of an academic training. Curr Sci. 2009;96(2):272-6.

43. Moreau KA. Has the new Kirkpatrick generation built a better hammer for our evaluation toolbox? Medical Teacher. 2017;39(9):999-1001. https://doi. org/10.1080/0142159X.2017.1337874.

44. Qualtrics software, Version [March, 2019] of Qualtrics. Copyright (๑ [2020] Qualtrics. Qualtrics, Provo, UT: https://www.qualtrics.com.

45. Clarke V, Braun V. Successful qualitative research: a practical guide for beginners. London: Sage; 2013. http://www.uk.sagepub.com/books/ Book233059.

46. Lindemann N. What's the average survey response rate? [2019 benchmark]. 2019. https://surveyanyplace.com/average-survey-response-rate/. Accessed 10 Aug 2020.

47. Dimova S, Prideaux R, Ball S, Harshfield A, Carpenter A, Marjanovic S. Enabling NHS staff to contribute to research: reflecting on current practice and informing future opportunities. The Healthcare Improvement Studies Institute. Washington, DC: RAND Corporation; 2018.

48. Society and College of Radiographers. Radiotherapy Radiographic Workforce Census. 2018. https://www.sor.org/learning/document-library/radiotherapyradiographic-workforce-census-2017. Accessed 14 Oct 2020.

49. Society and College of Radiographers. Diagnostic Radiography Workforce Report 2017. https://www.sor.org/learning/document-library/diagnosticradiography-uk-workforcereport-2017. Accessed 14 Oct 2020.

50. Harding KE, Stephens D, Taylor NF, Chu E, Wilby A. Development and Evaluation of an Allied Health Research Training Scheme. J Allied Health. 2010;39(4):e143-8.

51. Victorian Government, 1 Treasury Place, Melbourne. State of Victoria, Department of Health and Human Services. 2018. https://www2.health.vic. gov.au/health-workforce/allied-health-workforce/allied-health-research. Accessed 14 Oct 2020.

52. Currie M, King G, Rosenbaum P, Law M, Kertoy M, Specht J. A model of impacts of research partnerships in health and social services. Eval Prog Plann. 2005;28(4):400-12.

53. National Institute for Health Research. CQC inspections to give more exposure to clinical research taking place in NHS trusts. https://www.nihr.ac. uk/news/cqc-inspections-to-give-more-exposure-to-clinical-research-takingplace-in-nhs-trusts/20352. Accessed 20 May 2020.

\section{Publisher's Note}

Springer Nature remains neutral with regard to jurisdictional claims in published maps and institutional affiliations.

\section{Ready to submit your research? Choose BMC and benefit from:}

- fast, convenient online submission

- thorough peer review by experienced researchers in your field

- rapid publication on acceptance

- support for research data, including large and complex data types

- gold Open Access which fosters wider collaboration and increased citations

- maximum visibility for your research: over $100 \mathrm{M}$ website views per year

At BMC, research is always in progress.

Learn more biomedcentral.com/submissions 